San Jose State University

SJSU ScholarWorks

Master's Theses

Master's Theses and Graduate Research

1992

\title{
Perceptions of the role of occupational therapy and rehabilitation needs by persons with major burn injury
}

Lisa M. White

San Jose State University

Follow this and additional works at: https://scholarworks.sjsu.edu/etd_theses

\section{Recommended Citation}

White, Lisa M., "Perceptions of the role of occupational therapy and rehabilitation needs by persons with major burn injury" (1992). Master's Theses. 369.

DOI: https://doi.org/10.31979/etd.u5ex-2fbw

https://scholarworks.sjsu.edu/etd_theses/369

This Thesis is brought to you for free and open access by the Master's Theses and Graduate Research at SJSU ScholarWorks. It has been accepted for inclusion in Master's Theses by an authorized administrator of SJSU ScholarWorks. For more information, please contact scholarworks@sjsu.edu. 


\section{INFORMATION TO USERS}

This manuscript has been reproduced from the microfilm master. UMI films the text directly from the original or copy submitted. Thus, some thesis and dissertation copies are in typewriter face, while others may be from any type of computer printer.

The quality of this reproduction is dependent upon the quality of the copy submitted. Broken or indistinct print, colored or poor quality illustrations and photographs, print bleedthrough, substandard margins, and improper alignment can adversely affect reproduction.

In the unlikely event that the author did not send UMI a complete manuscript and there are missing pages, these will be noted. Also, if unauthorized copyright material had to be removed, a note will indicate the deletion.

Oversize materials (e.g., maps, drawings, charts) are reproduced by sectioning the original, beginning at the upper left-hand corner and continuing from left to right in equal sections with small overlaps. Each original is also photographed in one exposure and is included in reduced form at the back of the book.

Photographs included in the original manuscript have been reproduced xerographically in this copy. Higher quality $6 "$ " 9 " black and white photographic prints are available for any photographs or illustrations appearing in this copy for an additional charge. Contact UMI directly to order.

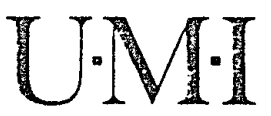



Order Number 1348730

Perceptions of the role of occupational therapy and rehabilitation needs by persons with major burn injury

White, Lisa Marie, M.S.

San Jose State University, 1992

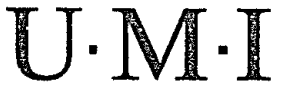





\title{
PERCEPTIONS OF THE ROLE OF OCCUPATIONAL THERAPY AND REHABILITATION NEEDS BY PERSONS WITH MAJOR BURN INJURY
}

\author{
A Thesis \\ Presented to \\ The Faculty of the Department of Occupational Therapy \\ San Jose State University \\ In Partial Fulfillment \\ of the Requirements for the Degree \\ Master of Science
}

By

Lisa M. White

May, 1992 
APPROVED FOR THE DEPARTMENT OF OCCUPATIONAL THERAPY

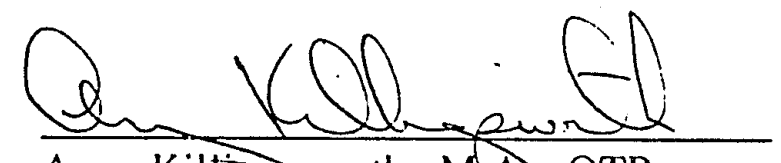
Amy Kiltimgsworh, M.A., OTR
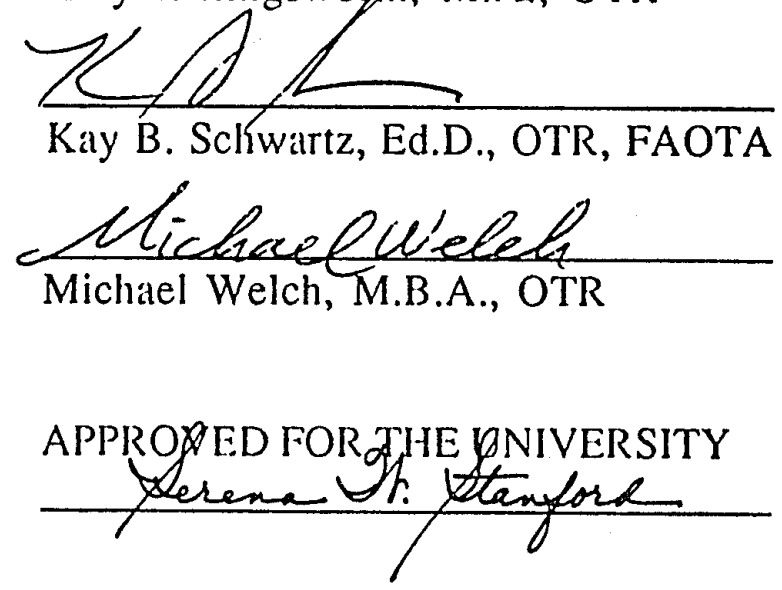


\begin{abstract}
PERCEPTIONS OF THE ROLE OF OCCUPATIONAL THERAPY AND REHABILITATION NEEDS BY PERSONS WITH MAJOR BURN INJURY

\section{by Lisa M. White}

As survival rates of patients with major burns increase it is becoming more important to study the course and quality of recovery. This study was conducted to identify the perceptions of occupational therapy and the rehabilitation process experienced by patients with major burn injury; and to assess the perceived needs of the patient with major burn injury during the rehabilitation process.

Fourteen persons with major burn injuries were interviewed. The majority of the participants revealed that they were unable to describe the role of occupational therapy, but were pleased with the rehabilitation experience. Responses regarding their discharge from the acute rehabilitation stay ranged from easy to poor. Participants indicated the following perceived needs in the rehabilitation process as important: having the purpose of and reason for treatment explained; alternative pain management strategies; speaking with another person with major burn injury; and a friendly, supportive relationship with the occupational therapist.
\end{abstract}




\section{ACKNOWLEDGEMENTS}

Many people have lent their assistance in various ways to this thesis. First, I would like to acknowledge Associate Professor Amy Killingsworth for all of the time, assistance and support provided to me throughout this project. As well, I would like to acknowledge Dr. Kay Schwartz and Michael Welch each for their unique expertise. Special acknowledgements are due Kim Webb and Webb and Associates who provided endless hours on the computer and added support throughout the writing of the project. Finally, a personal thank you to my parents and Tony for their continuous emotional support and faith. 


\section{TABLE OF CONTENTS}

ABSTRACT

Page

ACKNOWLEDGEMENTS

iii

LIST OF TABLE

iv

CHAPTER ONE: INTRODUCTION

vii

Purpose

Statement of the Problem

Objectives

Questions

Definitions

Assumptions

Limitations

Significance of the Study

3

4

4

5

CHAPTER TWO: REVIEW OF LITERATURE 7

Theoretical Framework $\quad 7$

Major Burn Injury 9

Major Burn Injury in Rehabilitation 10

Research in Burn Rehabilitation 12

Summary $\quad 14$

CHAPTER THREE: DESIGN AND METHODOLOGY 15

Design 15

Objectives 15

Questions 15

Subjects $\quad 16$

Collection Techniques 17

$\begin{array}{ll}\text { Analytical Techniques } & 17\end{array}$

CHAPTER FOUR: RESULTS 19

Demographic Data 19

Understanding of Occupational Therapy 20

Orientation/Understanding of Treatment

Approach

20 
Participation in Goal-Setting 22

Activities $\quad 23$

Pain Management 23

Follow-Up/Discharge 24

Rehabilitation-Impressions 25

Advice/Suggestions 26

Research Questions Answered 27

CHAPTER FIVE: RECOMMENDATIONS AND
IMPLICATIONS

Discussion $\quad 30$

Recommendations for Practice 34

Implications for Further Study 35

$\begin{array}{ll}\text { REFERENCES } & 36\end{array}$

\section{APPENDICES}

A San Jose State University Subjects Approval 40

B Hospital In-House Committee Approvals 43

C Subject Consent Forms 52

D Interview Guidelines 59 


\section{LIST OF TABLES}

$\begin{array}{ll}\text { Demographic Data } & 21\end{array}$

vii 


\section{CHAPTER 1}

\section{INTRODUCTION}

\section{Purpose}

The purpose of this study was threefold. First was to identify the perceptions of occupational therapy (O.T.) as seen by patients with burn injuries. Second was to identify the perceptions of the rehabilitation process experienced by patients with burn injury. Third was to assess the perceived needs of the patient during the rehabilitation process. The study also identified consistencies and trends which exist in those perceptions.

\section{Statement of the Problem}

Approximately two million individuals sustain burn injuries annually; over 100,000 burns are severe enough to require hospitalization (DiGregorio, 1984; Shenkman \& Stechmiller, 1987). The length of stay for patients with burns is three times longer than that for the average patient in acute hospitalization (O'Shaughnessy, 1981). As survival rates of patients with major burns increase it is becoming more important to study the course and quality of their recovery. The occupational therapist is an important and active member of the burn team involved in that rehabilitation. 
Raphael (1967) revealed that perspectives of consumers (patients) are different from those of health care providers. Knowledge of patients' perceptions is important in giving care. Information and data regarding the patients' perceptions of the rehabilitation process and of occupational therapy are lacking in the literature. There is need for research of the rehabilitation process, especially as perceived by the patient. To better serve clients in rehabilitation, it is necessary to gather information directly from those who receive the services. In so doing, the needs of the patients will be better met.

\section{Objectives}

The objectives of this pilot study were:

1. To describe the perceived needs of the patient with major burn injury during the rehabilitation process.

2. To identify consistencies which exist in the perceptions of the patient with major burn injury towards the rehabilitation process.

\section{Questions}

The study will attempt to answer the following questions:

1. What are the perceptions of the patient with major burn injury toward occupational therapy and the rehabilitation process? 
2. What are the perceived needs of the patient with major burn injury in rehabilitation?

\section{Definitions}

For the purpose of this study the following definitions were used: Activities of daily living (ADL): tasks of self-maintenance, mobility, communication, and home management that enable an individual to achieve personal independence in his/her environment (Pedretti, 1991).

Enabling activities: procedures that prepare the patient for occupational performance but are preliminary to the use of the performance skills (Pedretti, 1991).

Major burn injury: tissue injury resulting from excessive exposure to thermal, chemical, electrical, or radioactive agents. Cellular tissue and vascular destruction due to increase in temperature disrupting the body's skin protection which results in marked shifts of body fluid, temperature, and protection against infection (Thomas, 1985).

Patients, clients, consumers: for the purpose of this study, these terms will be used interchangeably defined as those individuals who receive occupational therapy services. -Rehabilitation: the process of treatment and education which leads the disabled individual to attainment of maximum function, a 
sense of well-being, and a personally satisfying level of independence.

Third degree burn: burns in which both the inner and outer layers of skin are destroyed with damage extending into underlying tissues (Thomas, 1985).

\section{Assumptions}

In proposing a pilot study of this topic, the researcher made the following assumptions:

1. The rehabilitation process had a significant impact on the sample group.

2. Persons who have major burn injuries would have sufficient memories of the rehabilitation process and the involvement of occupational therapists.

3. Persons who have major burn injuries would be able to communicate those perceptions accurately.

\section{Limitations}

This pilot study was designed to gather initial information of the perceptions of the patient with major burn injury. As such, the study had the following limitations:

1. It is not generalizable due to the small sample size. 
2. The findings with this small sample will require replication to extend the information beyond persons with major burn injuries.

3. The interpretation of the information is subject to researcher interpretation bias regarding the trends and similarities found in the data obtained.

\section{Significance of the Study}

There is limited research on the needs of the patients with major burn injury as perceived by the patients, as well as limited research on the perceptions of the patient with major burn injury towards the rehabilitation process. In conducting this pilot study, the researcher expected to address these issues and expand research in the areas of short- and long-term rehabilitation for burn injuries. Recovery from burn injury is a complicated and long-term process with continual adaptation to changes in appearance and function. Research in this area will help in understanding the perceptions of the patient with major burn injury towards the rehabilitation process, patient's needs, and the occupational therapist's involvement in the rehabilitation process.

The occupational therapist is an important and active member of the burn rehabilitation team which plays an important role in both the acute (initial) phase of recovery and the long-term rehabilitation. The information gained from this research will help occupational 
therapists to better serve persons with major burn injuries as well as aid in marketing occupational therapy.

It is believed that by utilizing research data to support marketing strategies, occupational therapy can meet the needs of the patient with major burn injury in a more efficient manner. The patient can become a resource for providing information that contributes to strategic decisions and the design of rehabilitation services. 


\section{CHAPTER 2}

\section{REVIEW OF LITERATURE}

This chapter delineates the theoretical components basic to this study. Literature regarding burn rehabilitation significant to the development and support of this study is reviewed.

Theoretical Framework

The Occupational Performance frame of reference was chosen as the theoretical base for this study. Occupational performance has been defined by the American Occupational Therapy Association (1974) and further expanded by Pedretti (1991) as the individual's ability to accomplish the tasks required by his or her role and related to his or her developmental stage. Occupational performance includes self-care, work, and play/leisure time performance. Occupational performance is further divided into performance components which are utilized for occupational performance. Performance components include motor function, sensory integrative functioning, cognitive functioning, psychological functioning, and social functioning. Occupational performance is influenced by life space, that is, the individual's cultural background and human or non-human environment. Deficits in performance components 
and/or life space may result in limitations in occupational performance (AOTA, 1974; Pedretti, 1991).

The Occupational Performance frame of reference was chosen for this study due to its holistic and inclusive framework for practice. This theoretical framework facilitates a thorough evaluation of a persons performance in self-care, work and play/leisure activities as affected by the five performance components and life space. Burn rehabilitation addresses the five occupational performance components. Primary physical concerns in burn rehabilitation include joint motion, strength, sensation, and disfigurement (Pedretti, 1991). In the occupational performance frame of reference these concerns are classified in the performance components of motor function and sensory-integrative function. Three major psychosocial aspects taken into account in burn rehabilitation are: epidemiology, acute hospital phase, and the long term adjustment and rehabilitation process (Tucker, 1986). These aspects are classified in the performance components of cognitive functioning, psychological functioning, and social functioning.

The five performance components correspond to the considerations for a holistic approach described by Reeves (1983). Reeves stated that in this approach one must consider the patient's physical and psychosocial status, current social surroundings and needs, previous lifestyle, and motivation. Occupational therapy is concerned with the performance components and how they 
enable/affect the performance skills (self-care, work and play/leisure activities) (Pedretti, 1991).

This study looks at the patient's perspectives of rehabilitation under the occupational performance frame of reference.

\section{Major Burn Injury}

Tucker (1986) stated that severe burns are the most traumatic of injuries, involving multiple physiological and psychological stresses. The burn injury is one of the most severe forms of trauma to the body (Pedretti, 1991) and is the third leading cause of accidental injury in the United States (Tucker, 1986). The victims are most often associated with lower class economics, improper housing, and dense populations (Tucker, 1986).

\section{Physical Aspects}

Pedretti (1985) reported that the primary physical concerns in burn rehabilitation include joint motion, strength, sensation and disfigurement. Cooper (1984) identified problems specific to burn patients as disfigurement, amputations, heterotrophic scarring, contractures, sensory loss, skin sensation, peripheral neuropathy, and pulmonary insufficiencies.

\section{Psychosocial Aspects}

- Tucker (1986) identified three major psychosocial aspects which need to be taken into account when a therapist is working with burn victims: epidemiology, the acute hospitalization phase, and the long- 
term adjustment and rehabilitation process. Information regarding epidemiology may indicate prior medical or psychiatric issues, stress and life events, as well as personality factors important to rehabilitation. During acute hospitalization, issues include emotional reactions, psychosis and organic brain syndrome, pain, family relationships, and aspects of management. In addition, long-term factors include skin problems, neuromuscular complications, and there is a strong emphasis on the psychosocial components during this phase, i.e., role performance, self-regard, and psychopathology (Tucker, 1986).

\section{Major Burn Injury in Rehabilitation}

Cooper (1984) stated that the recovery from burns is a complicated and long-term process with continual adaptations to changes in appearance and body function. Literature emphasizes the use of a holistic approach to rehabilitation of the burn patient due to the seriousness of the burn injury and the affect of all aspects of the person's existence (Cooper, 1984). According to Reeves (1983), the holistic approach must consider the patient's physical and psychological status, current social surroundings and needs, previous lifestyle, and motivation.

Rehabilitation concerns encompass maintenance of joint motion, prevention or minimizing of anatomic deformities, prevention of loss of body weight and muscle mass, and the return of the patient to 
work and activity as early and completely as possible (Boswick, 1987). The primary burn team usually consists of physicians, nurses, physical therapists, occupational therapists, dieticians, social workers, and psychiatrists (DiGregorio, 1984; Duncan \& Cathcart, 1988). DiGregorio (1984) stated that physical and occupational therapists are important and active members of the burn team. Duncan and Cathcart (1988) stressed the importance of communication between occupational and physical therapists since their treatment and primary goals are so closely interrelated.

\section{Occupational Therapy for Burn Injury}

Literature revealed that the focus of occupational therapy in burn rehabilitation is prevention of deformity and joint contractures, prevention of loss of range of motion and strength, increasing independence in activities of daily living and work skills, assisting in physical and emotional adjustment, minimizing scarring (fitting for pressure garments), and assisting the burn victim to achieve the optimal level of function consistent with the individual's desires, capacities, and abilities (McGourty, Givens, \& Fader, 1985; Pedretti, 1991; Reeves, 1983).

\section{The Role of the Patient in Burn Rehabilitation}

Fowler (1987) stressed the importance of the role of the burn patient in rehabilitation. Kaplan (1985) found that the ultimate success or failure of a treatment regimen often depended on the ability of the patient, family/caregiver, or both to correctly follow through on procedures and treatment after the patient is discharged 
from the hospital. The patient must be informed and educated about the rehabilitation process. According to Kaplan (1985), educational methods are most effective when they are geared toward the patient's understanding of the injury, his/her specific needs, problem areas, intelligence, and motivation.

Ekes and Marvin (1985) found that maintenance of patient cooperation is one of the biggest challenges for physical and occupational therapists. Therapists continue to seek more effective methods to deal with non-compliant patients (Ekes \& Marvin, 1985). Fowier (1987) stated the need for further research to better identify skills and techniques related to treatment compliance.

\section{Research in Burn Rehabilitation}

Cooper (1984) summarized the research priorities in behavioral areas for burn patients. He concluded that research in areas of short- and long-term recovery from burns is in its infancy and that more controlled research studies are greatly needed. Patients are often lost to follow-up care, and little is known about the kind and extent of rehabilitation problems encountered. Cooper also stressed that psychosocial research relating to medical conditions tends to adhere to a strictly experimental design format and is lacking in comprehensive understanding. He focused on the need for in-depth interviews and the collaboration of research designs. 
Research has emphasized the need to focus on postburn morbidity and to find ways to hasten the patient's return to normal patterns of life, due to the improved survival rates of burn victims (Reeves, 1983). The importance of further studying the course and quality of patients recovery and rehabilitation is stressed in the literature (Patterson et al., 1987). Previous studies have focused on physical and psychosocial adjustment (Browne et al., 1985; Chang \& Herzog, 1975; Wallace \& Lees, 1988), but little focus has been placed on the rehabilitation process. The primary sources of information have been chart notations by team members and not direct information from the patient (Browne et al., 1985; Chang \& Herzog, 1975; Johnstone, 1985; Sheffield, Irons, Mucha, Malec, Ilstrup, \& Stonnington, 1988).

The family's or caretaker's coping process and impact have been addressed (Adriaenssen, Boeckx, Gilles, Mertens, Nijs, \& Pyck, 1987; Cella, Perry, Kulchycky, \& Goodwin, 1988). Shenkman and Stechmiller (1987) reported striking incongruities between concerns of the burn patient and the caregiver regarding the rehabilitation process. Few studies have been conducted which use direct information from the patient. Those studies that have been conducted have been criticized since information has been obtained using rating scales and psychometric tests rather that direct interviews with the burn patient to identify individual perspectives (Andreason \& Norris, 1971; Andreason \& Norris, 1972; Patterson et al., 1987; Wallace \& Lees, 1988). 


\section{Summary}

Rehabilitation concerns for the person with major burn injury encompass maintenance of joint motion, prevention or minimizing of anatomic deformities, prevention of loss of body weight and muscle mass, and the return of the patient to work and activity as early and completely as possible. In so doing, the rehabilitation team addresses physical and psychological concerns. Research has been conducted in these areas, yet primarily through the use of chart notations, family or caretaker interviews, psychometric tests, or rating scales. Little research has been completed using direct interviews to identify individual perspectives.

Literature indicates the need for research involving direct interviews with persons with major burn injury. Literature also supports the need for research involving the rehabilitation process as experienced by the patient with major burn injury. 


\section{CHAPTER 3}

\section{DESIGN AND METHODOLOGY}

This chapter deals primarily with the collection and treatment of the data. It includes a description of the design, the participants, and the collection and computational techniques.

\section{Design}

The design was non-experimental using in-depth interviews. It was conducted as an exploratory pilot study.

\section{Objectives}

The objectives of this pilot study were:

1. To describe the perceived needs of the patient with major burn injury during the rehabilitation process.

2. To identify consistencies which exist in the perceptions of the patient with major burn injury towards the rehabilitation process.

\section{Questions}

The study will attempt to answer the following questions: 
1. What are the perceptions of the patient with major burn injury towards occupational therapy and the rehabilitation process?

2. What are the perceived needs of the patient with major burn injury in rehabilitation?

\section{Subjects}

Selection criteria for subjects included: a diagnosis of major burn injury, i.e., third degree burns of $30 \%$ or greater total body surface area, and/or burns involving specialized areas of the body (hands and/or face); must have progressed through a significant portion of the recovery process, 2-5 years post injury; and were identified by the researcher with assistance from a representative from the hospitals mentioned above.

One hundred and one potential participant names were provided by three hospitals: 38 by St. Francis Memorial Hospital; 33 by Santa Clara Valley Medical Hospital; and 30 by Alta Bates-Herrick Hospital. Of these potential participants, 14 were able to participate in the study. Fourty-one were deceased or had moved with no forwarding address. Nine had moved too far from the area to be interviewed. Nineteen were unable to be contacted for various reasons. Eighteen declined participation secondary to legal or personal reasons. 


\section{Collection Techniques}

Data collection commenced upon approval from the San Jose State University Human Subjects Committee (see Appendix A), the Hospital In-House Committees (see Appendix B) and the subjects' consent (see Appendix C). With the subjects' prior knowledge and permission, interviews were audiotape recorded, and the researcher also recorded notes in order to document all information exchanged during the interviews. Data were collected by individual, in-depth, interviews, using a general outline of topics addressed (see Appendix D). The general outline of topics was derived primarily through the information gathered in the literature. The outline of questions were designed to: provide basic background information; stimulate discussion of the rehabilitation process and occupational therapy treatment received; and to derive the needs and wants of the patient with major burn injury. The objective of the researcher was inclusion of all necessary data. The interviews varied in length from 45 to 150 minutes.

\section{Analytical Techniques}

Interview data were described and presented in narrative form according to classifications of the interview guide questions. The researcher sought to identify the subjects' perceptions of the rehabilitation process, their perceived needs for rehabilitation, and 
occupational therapy involvement in the rehabilitation process.

Demographic data were summarized using descriptive statistics. 


\section{CHAPTER 4}

\section{RESULTS}

This chapter presents the analysis and interpretation of data. The data collected were described according to nine areas of responses generated from the interviews. The areas are demographic data, understanding of occupational therapy, orientation/understanding of treatment approach, participation in goal-setting, activities, pain management, number of therapists, follow-up/discharge, rehabilitation-impressions, and advice/suggestions.

\section{Demographic Data}

The fourteen participants were persons with major burn injuries (11 male and 3 female). Seven had received therapy through Alta Bates-Herrick Hospital, four through Santa Clara Valley Medical Center, and three through Saint Francis Hospital, all during the period 1985-1988. The ages ranged from 20 to 60 years.

All subjects were diagnosed with third degree burns over $30 \%$ or more of the body, and/or involvement of the hands or face. The length of stay in the burn units ranged from 16 to 120 days. All participants received occupational therapy during their stay, and some form of continuing therapy upon discharge. Following their 
injury five participants were employed by the same employer or in the same occupation as employed prior to their injury; six participants were employed in different occupations; and three participants were either unemployed or disabled (see Table 1).

\section{Understanding of Occupational Therapy}

Ten (71\%) participants were not able to define or describe occupational therapy, did not recall receiving a description or definition of occupational therapy, and were not able to differentiate between occupational therapy and physical therapy. Two of these ten participants said they received a definition of occupational therapy yet felt it was still not clear, and did not notice a difference in the treatment approaches of occupational and physical therapy. Four participants (29\%) knew that the goal of occupational therapy was to increase the level of function in activities of daily living $(\mathrm{ADL})$, and were able to distinguish between occupational and physical therapy.

\section{Orientation/Understanding of Treatment Approach}

All of the participants commented that their occupational therapists explained the purpose and reason for their treatment approach from the beginning. Nine (64\%) participants felt this was very helpful. Two (14\%) commented that, even with the explanation, 
Table 1

Demographic Data

\begin{tabular}{|c|c|c|c|c|}
\hline \multirow[b]{2}{*}{ Gender } & \multirow[b]{2}{*}{ Age } & \multirow{2}{*}{$\begin{array}{c}\text { Acute } \\
\text { Length of Stay }\end{array}$} & \multicolumn{2}{|c|}{ Occupation } \\
\hline & & & Prior & Post \\
\hline $\mathbf{M}$ & 20 & 45 days & Student & Unemployed \\
\hline $\mathbf{M}$ & 22 & 16 days & Electrician & Different \\
\hline $\mathbf{M}$ & 24 & 32 days & NA & Unemployed \\
\hline $\mathbf{F}$ & 25 & 32 days & Student & Same \\
\hline $\mathbf{M}$ & 27 & 14 days & Business & Same \\
\hline $\begin{array}{l}M \\
M\end{array}$ & $\begin{array}{l}32 \\
40\end{array}$ & $\begin{array}{l}35 \text { days } \\
33 \text { days }\end{array}$ & $\begin{array}{l}\text { Construction } \\
\text { Electrician }\end{array}$ & $\begin{array}{l}\text { Same } \\
\text { Same }\end{array}$ \\
\hline $\mathbf{M}$ & 41 & 32 days & Construction & Different \\
\hline $\mathbf{M}$ & 42 & 34 days & $\begin{array}{l}\text { Electrical } \\
\text { Linesman }\end{array}$ & Different \\
\hline $\mathrm{F}$ & 43 & 120 days & Housewife & Disabled \\
\hline $\begin{array}{l}\mathbf{M} \\
\mathbf{M}\end{array}$ & $\begin{array}{l}45 \\
52\end{array}$ & $\begin{array}{l}35 \text { days } \\
60 \text { days }\end{array}$ & $\begin{array}{l}\text { Engineer } \\
\mathrm{NA}\end{array}$ & $\begin{array}{l}\text { Different } \\
\text { Different }\end{array}$ \\
\hline $\begin{array}{l}\mathbf{M} \\
\mathrm{F}\end{array}$ & $\begin{array}{l}56 \\
60\end{array}$ & $\begin{array}{l}60 \text { days } \\
32 \text { days }\end{array}$ & $\begin{array}{l}\text { NA } \\
\text { Retired }\end{array}$ & $\begin{array}{l}\text { Different } \\
\text { Same }\end{array}$ \\
\hline
\end{tabular}


the therapy was so painful it was difficult to understand the importance at that time, although they were later able to understand. Four (29\%) participants mentioned spending the first meeting with the therapist talking not only about therapy and goals, but finding common interests to discuss as a diversion from the pain during treatment. Three $(21 \%)$ mentioned receiving written information which was helpful because they could review the information later at their convenience or when ready.

\section{Participation in Goal-Setting}

Nine (64\%) participants felt they worked together with their occupational therapists in setting goals for therapy. Of these nine, seven commented on the importance of this procedure for setting up and following through with home programs. Some comments were: "We worked together to problem solve and I was taught to do my own follow-through." "Once I knew what was going on and how I could participate, therapy was much, much better." "It really helped to set personal goals." One (7\%) participant felt there was not much "teamwork" between themselves and their occupational therapist. Four (29\%) participants had no comment. 


\section{Activities}

Participants' descriptions of their therapy fell primarily into the categories of exercises, range of motion (ROM), and enabling activities. Thirteen (93\%) participated in some type of enabling activity. Some comments regarding participants' involvement in enabling activities were: "They (enabling activities) were frustrating yet made me work harder and brought reality to my injury." "The activities helped make it fun and get my mind off of it all." "The exercises really helped get my mind off of the injury." "I first started using my arm (affected limb) in my hobby at home which was excellent therapy........kept me occupied."

Only four (29\%) participated in ADL training. Some comments regarding $A D L$ training after discharge were: "I was first introduced to activities in my own ADL and work" and "Some of the best therapy was at home doing my own thing."

\section{Pain Management}

Four (29\%) participants reported that pain management was not an issue after the initial phase where morphine was used. Six (43\%) were still having pain 4-5 years post-burn injury. These $43 \%$ said an introduction to alternative approaches in pain management, other than medication, would have been beneficial. One (7\%) commented that it would be "an excellent source of knowledge." Only two (14\%) 
participants recalled having any alternative methods to pain management, other than medication, introduced to them; one of these never received any follow through and the other tried the approach with no success. Two (14\%) participants had no comment.

Follow-Up/Discharge

Nine (64\%) participants are now working. Four (29\%) participants are not working, and one (7\%) is a student. Two of the nine participants who were working received vocational training through their employment. The other seven of the nine participants working received no professional vocational training. Four of the nine participants who were still working returned to the same job occupied prior to the injury; two returned to the same employer in a different position; and three changed occupations and employers. One of the four participants not working did not receive any vocational evaluation or training, but would like to have received them. Two of the four participants who were not working had retired after their injury and one was disabled.

There was varied response to discharge and returning home. One $(7 \%)$ person said his discharge to home was very poorly planned and found that he and his wife learned to do and adapt on their own without any assistance. Seven (50\%) participants felt ready for discharge, yet were still scared. One (7\%) person who received ADL training such as dressing, meal preparation, toileting and stair 
management was very aware of what to expect for the transition to home. Three (21\%) participants had a good home program set up for continued therapy at home, and found this helpful. Two (14\%) participants had no comment.

\section{Rehabilitation-Impressions}

Thirteen (93\%) of the participants expressed satisfaction with their rehabilitation experience. Two factors which emerged as important were: opportunity to speak with another person with major burn injury who had progressed further along in his/her rehabilitation and recovery; and the friendship, support and bond developed with the staff and therapists.

Three (21\%) participants were able to talk to another person with burn injury who had progressed farther in recovery. These participants expressed the following: "I learned more from others who had been through the experience than from the therapists." "It was the best thing that could have happened." "It reinforced the idea that this wasn't going to last forever, and gave me an idea of how long." "It was very helpful psychologically." The other 11 (79\%) participants who were not able to talk with another victim said that such a talk may have helped them answer some questions the that staff could not, would have emphasized the importance of therapy from the beginning, and perhaps would have given them more hope. 
Comments regarding participants' relationships with their occupational therapists were: "They (the therapists) were more helpful than the psychiatrist in my emotional support because they were more involved." "The spirit, niceness, and support of the staff helped the most." "I was impressed with the niceness of the people concerned with me as a person rather than a patient."

\section{Advice/Suggestions}

The final question of the interview was "what advice would you give an incoming therapist to the field of burn rehabilitation?". Nine (64\%) participants found it very important for the occupational therapist to educate the patient on the purpose of the therapy, to provide information regarding the long term consequences of the injury, and to inform the patient of the importance of, and reason for, proper follow through. Four (29\%) participants suggested providing the first meeting between the therapist and the patient as just time to talk, gain a common ground/interest, and introduce the avenue to provide information.

Five $(36 \%)$ participants commented on the importance of the therapist's personality. They found the following very important: humor; to become personal and gain a "friendly" ground; to work with the patient, not on the patient; and to be patient. Yet, within all of these qualities, the therapist should continue to be firm. 
Four (29\%) participants strongly advised the therapist to consider the other issues that affect the patient other than the injury itself. For example, loss of loved ones, loss of a job or home or belongings, and financial problems.

Four (29\%) participants advised the therapists to remember that each person is different, and each approach to therapy should be individualized. Some comments were: "Pay attention to the patient's ideas and ways of adaptation. There's not just one 'right' way." "Treat the whole person, not just the burn." "I wanted my therapist to hold off on all that adaptive equipment until he/she knew what I could or couldn't do."

Finally, four (29\%) participants advised the occupational therapist to be available to the patient for advice and support. Often the therapist is working so closely with the patient that they are the one whom the patient can turn to for comfort, venting, and advice (in areas other than therapy, as well).

\section{Research Questions Answered}

1. What are the perceptions of the patient with major burn injury towards occupational therapy and the rehabilitation process?

The participants with major burn injury indicated the following perceptions of occupational therapy and the rehabilitation process: 
Ten $(71 \%)$ of the participants were unable to explain the role of occupational therapy or to distinguish between occupational and physical therapy. Four (29\%) participants were able to provide a description of occupational therapy and distinguish between occupational and physical therapy. There were positive comments from the participants towards the use of enabling activities and ADL.

Thirteen (93\%) participants reported being very pleased with their rehabilitation experience. One (7\%) participant was not pleased with his/her rehabilitation experience. Participants indicated varied responses to discharge from their acute rehabilitation stay. Seven $(50 \%)$ of the participants reported feeling prepared, yet frightened, for their discharge. One (7\%) participant found the transition to be very easy, and one (7\%) participant rated his/her discharge as very poor. Five (36\%) participants had no comment.

2. What are the perceived needs of the patient with major burn injury in rehabilitation?

The participants with major burn injury indicated the following perceived needs in rehabilitation:

Nine (64\%) participants indicated the importance to having the purpose of and the reason for treatment explained to them. Of these participants, two (22\%) indicated the need to have this 
information provided verbally throughout the rehabilitation process and three (33\%) participants found the need for information to be provided in written form. As well, nine (64\%) participants found importance in working together with their occupational therapists in setting goals.

Seven (50\%) participants indicated a need for an alternative source to pain management other than medication. These seven participants were still experiencing pain 1-4 years post injury.

The importance of speaking with another person with major burn injury who had progressed further along in his/her rehabilitation and recovery was indicated as a need by all fourteen participants. Three (21\%) participants were able to speak to another person with major burn injury. The other 11 (79\%) participants were not able to speak to another person with major burn injury, but commented that such an experience would have been beneficial.

Also indicated was the importance of the friendship, support and bond between the therapists and the patient. Four (29\%) participants advised the occupational therapist to be available to the patient for advice and support. Five (36\%) participants commented on the importance of the therapist's personality, primarily having a sense of humor, being personal with the patient on a friendly basis, yet firm in their therapy. 


\section{CHAPTER 5}

\section{RECOMMENDATIONS AND IMPLICATIONS}

This chapter provides a discussion of the findings and recommendations which were described as a result of the data analysis. It also includes recommendations for practice and implications for further study.

\section{Discussion}

\section{Perceptions of Occupational Therapy and the Rehabilitation Process}

The majority of participants interviewed were not able to define or describe occupational therapy, did not recall receiving a description or definition of occupational therapy, and were not able to differentiate between occupational and physical therapy. Two participants said they received a definition of occupational therapy yet felt it was still not clear, and did not notice a difference in the treatment approaches of occupational and physical therapy. A majority of participants interviewed expressed that it was important for the occupational therapist to educate the patient in the purpose of occupational therapy, provide information regarding long-term consequences of the injury, and inform the patient of the importance and reason for proper follow through. Participants suggested 
providing written and verbal information throughout the rehabilitation experience. These comments indicate a need for occupational therapists to provide clear, continuous information for the patient regarding occupational therapy treatment approaches and possibly provide this information in written form for review by the patient. Further research is indicated to investigate effective methods of conveying this information and most effective time for delivery.

The comments from participants on the enabling activities or ADL in which they participated supported the theory base of occupational therapy as described through the Occupational Performance frame of reference. Comments such as "They (enabling activities) were frustrating yet made me work harder and brought reality to my injury" support the use of enabling activities as procedures to prepare the patient for occupational performance.

The majority of treatments involved enabling activities possibly indicating that the performance components of motor function and sensory integrative function need to be the focus of treatment prior to the performance skills of $\mathrm{ADL}$ training. Very few participants were directly involved in ADL training. Further research is indicated to investigate the use of enabling activities versus the use of ADL in the treatment of the patient with major burn injury.

Half of the participants felt prepared for their discharge. Of these, all commented on still feeling frightened yet prepared. The 
importance of a good home program upon discharge was indicated to ease the transition upon discharge.

The majority of participants expressed satisfaction with their rehabilitation experience.

\section{Perceived Needs in Rehabilitation}

Data from the interviews indicated that the purpose and reason for therapy were being explained to patients and supported the importance of this aspect of service delivery. The participants who brought up the issue of not being mentally prepared for the information at the time that it was given addressed the importance of providing information continuously, as well as providing written information to be read at the patient's discretion. Further research is again indicated to investigate the most effective methods and time for delivery of information to the patient with major burn injury.

Participants indicated the importance of being an active participant in the treatment process. This may be achieved by eliciting the patient's assistance in setting goals, not setting goals for them. The therapist serves as the provider of education, knowledge and experience for the patient to set and meet their own goals. This can elicit motivation, involvement, and follow through.

Ekes and Marvin (1985) commented on the maintenance of the patient's cooperation as one of the biggest challenges for therapists. The participation of patients in their own goal-setting may be one 
method of improving cooperation. Likewise, Kaplan (1985) pointed out that the ultimate success or failure of a patient's rehabilitation is correlated to the ability of the patient (and/or family

members/caregivers) to follow-through on procedures and treatment. Nine of the participants commented on the importance of participation in goal-setting for follow-through with home programs which supported Kaplan's research.

There was an indicated need for alternative and/or additional methods to pain management other than medication. The pain involved in a burn injury extends far beyond the initial acute stage of injury at which time medical management of the pain is required. However, since the pain involved in different stages of burn injury can and do evolve over years, other sources of pain management could be explored and initiated in therapy. Further research of effective methods of pain management is indicated.

The importance of speaking with another person with major burn injury who had progressed further along in his/her rehabilitation and recovery was indicated by all fourteen participants. This opportunity is supported through the Occupational Performance frame of reference as a treatment approach for the performance component of psychological functioning affecting occupational performance and performance skills. Participants' perceived needs support the use of this opportunity as part of their rehabilitation experience. 
Four participants suggested providing the first meeting between the occupational therapist and the patient as time to talk, gain a common ground/interest, and introduce the avenue for information. Other suggestions were for the occupational therapist to try to maintain a friendly relationship with the patient as well as to be available as a source for advice and support; to consider the other issues that affect the patient other then the injury itself; and to remember that each person is different, and each approach to therapy should be individualized. This approach is supported in the Occupational Performance frame of reference through the importance and influence of the person's Life Space, that is, the cultural background and human or non-human environment.

\section{Recommendations for Practice}

Based on the perceptions of persons with major burn injury towards occupational therapy, its role in rehabilitation, and rehabilitation needs, the following recommendations are made:

1. Provide information and resources throughout the rehabilitation process to increase the patient's knowledge and understanding of occupational therapy.

2. Provide orientation for the patient to the therapeutic approach to provide purpose and reason to therapy.

3. Provide continuous verbal and/or written information about the therapeutic process. 
4. Promote the use of enabling activities in therapy. Increase the use of $\mathrm{ADL}$ training in the therapeutic process.

5. Provide a good home program upon discharge.

6. Involve the patient in goal setting.

7. Incorporate the opportunity for the patient to speak with a person with major burn injury who has further progressed in their recovery.

8. Create a positive therapeutic relationship.

9. Recognize the individuality of the patient and incorporate it into treatment.

\section{Implications for Further Study}

1. Further explore effective methods of conveying information and the most effective time of delivery of information for the person with major burn injury in rehabilitation.

2. Further explore the use of enabling activities and ADL in treatment of the patient with major burn injury.

3. Further explore effective and alternative/additional methods for pain management, especially for long-term pain management. 


\section{REFERENCES}

Adriaenssen, P., Boeckx, W., Gilles, B., Mertens, S., Nijs, P., \& Pyck, K. (1987). Impact of facial burns on the family. Scandinavian Journal of Plastic Reconstructive Surgery, 21, 303-305.

American Occupational Therapy Association (1974). A curriculum guide for occupational therapy educators. Rockville, MD: Author.

Andreason, N. J. C., \& Norris, A. S. (1971). Incidence of long-term psychiatric complications in severely burned adults. Annual Surgery, 174, 785-791.

Andreason, N. J. C., \& Norris, A. S. (1972). Long-term adjustment and adaptation mechanisms in severely burned adults. Journal of Nervous Mental Disorders, $154,352-357$.

Boswick, J. A. (1987). Comprehensive rehabilitation after burn injury. Surgical Clinics of North America, 67 (1), 159-166.

Browne, G., Byrne, C., Brown, B., Pennock, M., Streiner, D., Roberts, R., Eyles, P., Truscott, D., \& Dabbs, R. (1985). Psychosocial adjustment of burn survivors. Burns Including Thermal Injury, 12 (1), 28-35. Cella, D. F., Perry, S. W., Kulchycky, S., \& Goodwin, C. (1988). Stress and coping in relatives of burn patients: A longitudinal study. Hospital and Community Psychiatry, 39 (2), 159-166.

Chang, F. C., \& Herzog, B. S. (1976). Burn morbidity: A follow-up study of physical and psychological disability. Annual of Surgery, 183, 34-37. 
Cooper, M. K. (1984). What are the research priorities in behavioral areas for burn patients? The Journal of Trauma, 24 (9), S197S201.

DiGregorio, V. R. (Ed.). (1984). Rehabilitation of the burn patient. New York: Churchill Livingstone.

Duncan, C. E., \& Cathcart, M. E. (1988). A multi-disciplinary model for burn rehabilitation. Journal of Burn Care and Rehabilitation, 2 (2), 191-193.

Ekes, A., \& Marvin, J. A. (1985). Burn patient cooperation in physical and occupational therapy. Journal of Burn Care and Rehabilitation, $\underline{6}(3), 246-249$.

Fowler, D. (1987). Australian occupational therapy: Current trends and future considerations in burn rehabilitation. Journal of Burn Care and Rehabilitation, 8 8 (5), 415-417.

Johnstone, P. (1985). Follow-up of burned patients in the United Kingdom. Burns Including Thermal Injury, 11, 216-219.

Kaplan, S. H. (1985). Patient education techniques used at burn center. The American Journal of Occupational Therapy, 39, 655658.

McGourty, L. K., Givens, A., \& Fader, P. B. (1985). Roles and functions of occupational therapy in burn care delivery. The American Journal of Occupational Therapy, 39, 791-793.

O'Shaughnessy, E. J. (1981). Burns. In Stolov, W. C., \& Clowers, M. R. (Eds.), Handbook of severe disability (pp. 409-418). University of 
Washington: U.S. Department of Education and Rehabilitation Services Administration.

Patterson, D. R., Questad, K. A., Boltwood, M. D., Covey, M. H., deLateur, B. J., Dutcher, K. A., Heimbach, D. M., \& Marvin, J. A. (1987). Patient self-reports three months after sustaining a major burn. Journal of Burn Care and Rehabilitation, 8⑷, 274-279.

Pedretti, L. W. (1991). Occupational therapy: Practice skills for physical dysfunction (3rd ed.). St. Louis: C.V. Mosby. Raphael, W. (1967). Do we know what the patients think? A survey comparing the views of patients, staff and committee members. International Journal of Nursing Studies, 4, 209-222. Reeves, S. O. (1983). Occupational therapy in burn treatment. In R. E. Salisbury, N. M. Newman \& P. G. Dingeldein (Eds.), Manual of burn therapeutics: An interdisciplinary approach (pp. 179-195). Boston: Little, Brown, \& Co.

Sheffield, C. G., Irons, G. B., Mucha, P., Malec, J. F., Ilstrup, D. M., \& Stonnington, H. H. (1988). Physical and psychological outcome after burns. Journal of Burn Care and Rehabilitation, 9 (2), 172178.

Shenkman, B., \& Stechmiller, J. (1987). Patient and family percepted functioning after discharge from a burn unit. Heart and Lung, 16 (3), 490-496.

Thomas, C. L. (Ed.). (1985). Taber's Cyclopedic Medical Dictionary.

Philadelphia: F.A. Davis. 
Tucker, P. (1986). The burn victim - a review of psychosocial issues. Australian and new Zealand Journal of Psychiatry, 20, 413-420.

Wallace, L. M., \& Lees, J. (1988). A psychological follow-up study of adult patients discharged from a British burn unit. Burns Including Thermal Injury, 14 (1), 39-45. 
Olfice of the Academic Vice President - Assoclate Acadomic Vico President - Grodualo Siudles and Rezeorch

One Washinglon Square - San Jose, Calilornia 95192-0025 - 408/924-2480

July 20, 1989

Lisa White

115 Walford Drive

Moraga, CA 94556

Dear Lisa:

Your human subjects protocol number 7523 has received final approval. Attached is a copy of the final approval form with the signature of the Chairperson of the Human subjects Institutional Review Board and my approval.

The Human Subjects Institutional Review Board must be notified in writing of any changes to this approved protocol, and approval must be granted in writing before any change is instituted.

Congratulations and good luck with your research!

Sincerely,

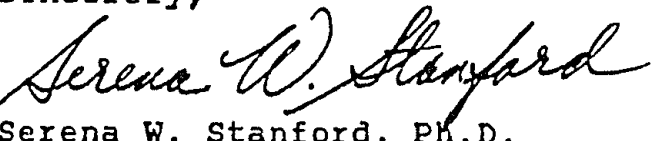

Serena $W$. Stanford, Ph.D.

AAVP for Graduate studies \& Research

Attachment 


\section{SAN JOSE STATE UNIVERSITY GRADUATE STUDIES AND RESEARCH}

\section{HUMAN SUBJECTS INSTITUTIONAL REVIEW ROARD PROJECT PROPOSAL REVIEW}

Regular Review $\square$

Expedited Reviow

Deadline Date

I. the undersigned member of the San Jose State University Human Subjects Institutional Review Board, have reviewed the following proposal submilted to the Board on by:

PRINCIPAL INVESTIGATOR: LISA WHITE

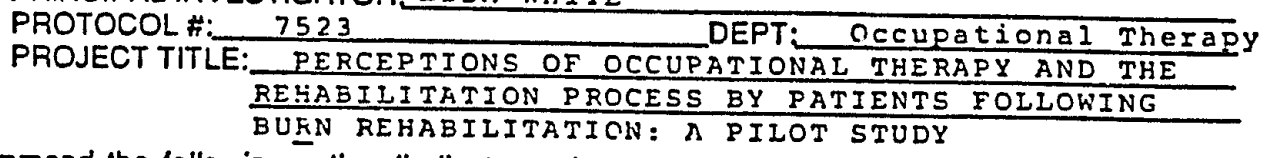

I recommend the following action (indicate one):

1. Approved for clearance as involving minimal risk to Human Subjects.

2. Approved for clearance with risk to Human Subjects.

3. Approval depends upon the satisfactory completion of the

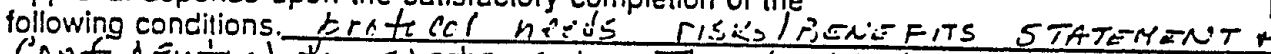
Confideutinlite statemelit. This iokld ber a daintul

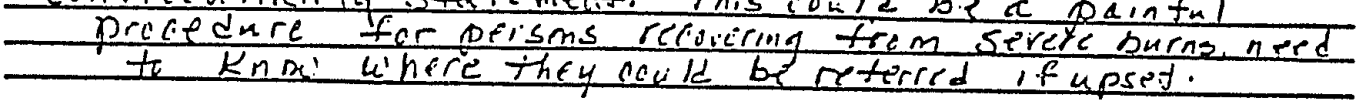

4. I have serious concerns about this protocol and it should go before the full committee to review.

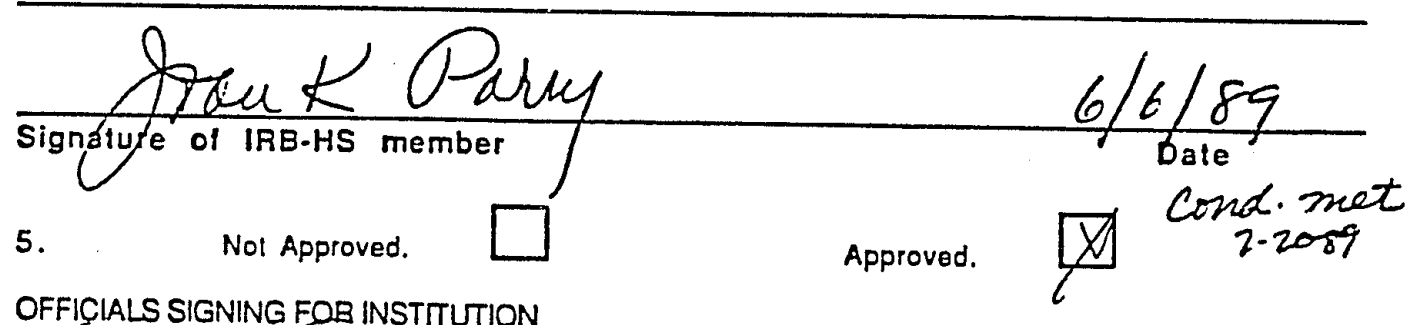

OFFICIALS SIGNING FOB INSTTIUTION

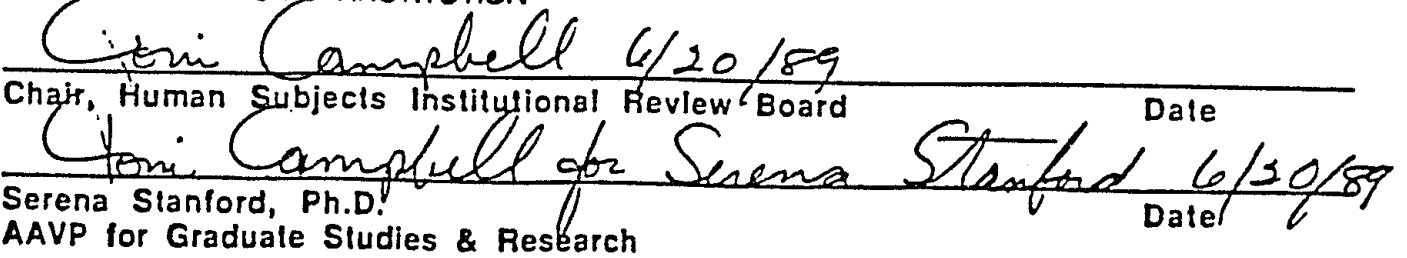

Please relum 10: Graduate Studies and Research Olfice, Administration Building 150, San Jose State University. One Washington Square, San Jose, CA 95192.0139

(408) 924.2480 
APPENDIX B

HOSPITAL IN-HOUSE COMMITTEE APPROVALS 
\begin{tabular}{|c|c|c|c|}
\hline 1 & Alta Bates - Herrick Hospital \\
2001 Dwight Way - Berkeley, CA 94704 • (415) 845-0130
\end{tabular}

May 16, 1989

Lisa White

845 Blair Avenue, \#1

Sunnyvale, CA 94087

Dear Lisa:

This letter serves as an official approval of your request to interview burn patients.

Since Michael Welsh is leaving, you will be working with the new occupational therapist for the Bum Center. Please contact Joan Carboneau, who is the manager of occupational therapy at Alta Bates, at 540-1498, and she will help you proceed with your project.

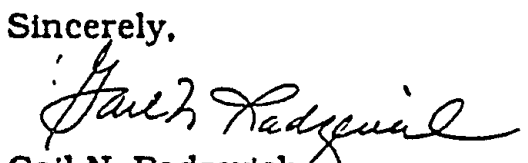

Gail N. Radzevich

Director of Publfe Relations

cc: J. Carboneau 


\section{Saint Francis Memorial Hospital}

Posl Oflice Box 7726 Sinn Fruncisco. Culilurnia 94220 (485) 775.4321

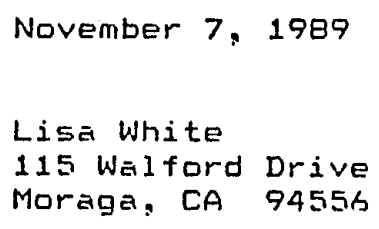

The Committee is to be notified of the completion date of the study; arid a timely, final report on the conduct arid results of the trial is required.

The aforementioned approval is conditional upon completion of any pre-investigational requirements by the FDA. 
Lisa White

Fage 2.

This is also to advise you that the Institutional fieview Commitee of saint Francis Memorial Hospital and its activities are subject to review and approval by the Federal Drug Administation, and has been subjected to routine on site visits by representatives from this agency. To date, the committee and its activities have ongoing approval, after review, of this type of protocal.

Do not hesitate to contact us if we can furnish additional assistance or information

Sincerely yours,

INSTITUTIONAL FIEVIEW COMMITTEE

Qames A. Kauth, Mis

James H. Kaulth, M.D.

Chairman

JHF: ir

cc: Claire Dyer 


\section{SAINT FRANCIS \\ MEMORIAL HQSPITAL}

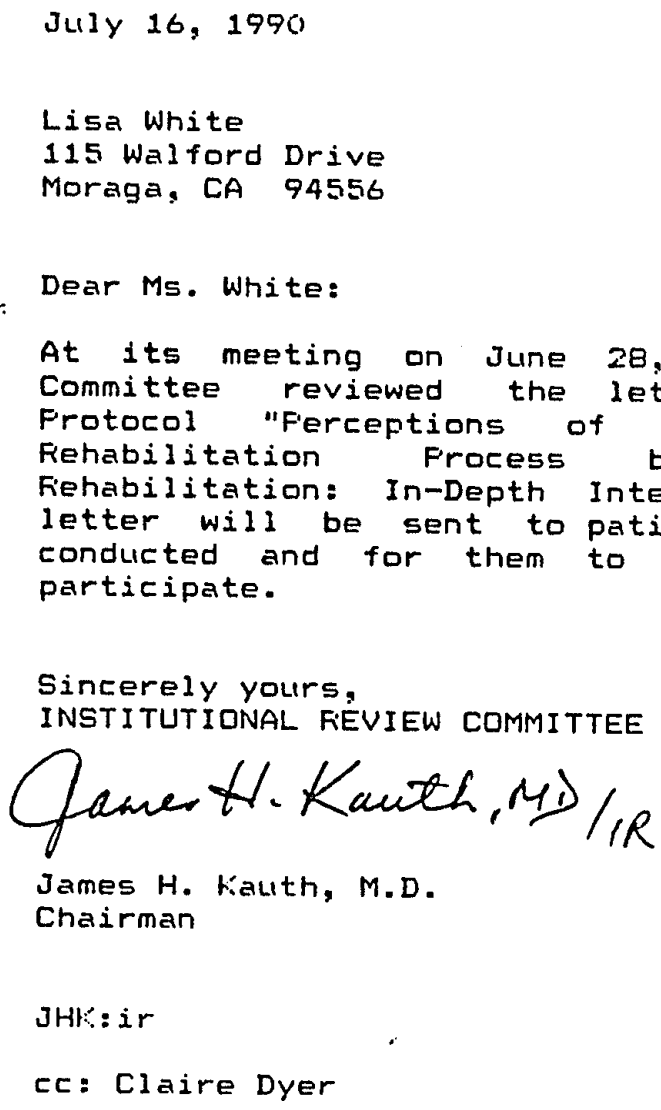




\section{SAINT FRANCIS \\ MEMORIAL HQSPITTAL}

April 27, 1990

James Kauth, MD
Chairman
Institutional Review, Committee
Saint Francis Memorial Hospital

Dear Dr. Kauth:

I have been in contact with Ms. Lisa white. She thanks you and the committee for approving without modification her study entitled: "Perceptions of Occupational Therapy and the Rehabilitation Process by Patients Following Burn Rehabilitation: In-Depth Interviews."

The committee did request that a "letter of clarification" be sent to the patients stating that a study is being conducted and to let us know if they do not want to participate. Attached is a copy of the letter.

Ms. White has already conducted this study with the Alta Bates Burn Center. I am delighted we can assist her with her study and perhaps become part of the improving the needs and services of the burn patient.

Thnak you. We will keep you informed on the progress of
the study.

sincerely,

Claire Dyer, RN

Clinical Manager

Bothin Burn Center

CD:st

cc: Lisa White

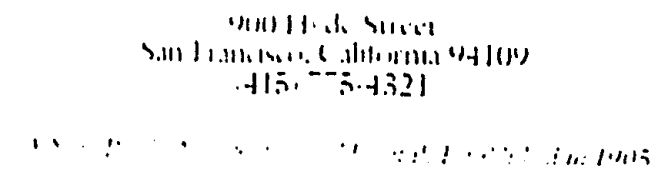


1347 Navellier St. El Cerrito, CA 94530 H-(415) 233-7997

$W-(415) \quad 540-4570$

Sept. 9, 1990

Dear Potential Participant,

I am a graduate stident completing my Master of Science degree in Occupational Therapy at San Jose State University. As part of my studies I am conducting research for my thesis involving persons who have received rehabilitation therapies following a major burn injury.

The purpose of this research is primarily to receive information that will be helpful and useful to therapists in better meeting people's needs through therapy. I am interested in identifying the perceptions that you have of occupational therapy, and other therapies involved in rehabilitation following a major burn. I am interested in what you perceive as positive and/or negative about your therapy experience, and what helped you the most or could have helped you more. I am interested in your views, knowledge, and experience.

Your involvement in this study will just be a one time interview that will last approximately two hours. I will meet with you at your location and time of convenience, and will ask questions regarding your perceptions and experiencess in the rehabilitation process. Any information you share with me will remain confidentially anonymous.

This is a very important study to me, and I believe you can help me make a difference in other's lives who may be faced with the same challenges that you have. Please contact me (at the above numbers) or Claire. Dyer (at St. Frahcis Hospital Burn Center (415) $775-4321$ ext. 4759) if you do not want to contact you soon.

Thank you for your consideration and potential participation. I hope I will be speaking to you soon.

Sincerely,

Lisa White 


\section{CALIFORNIA INSTITUTE for MEDICAL RESEARCH \\ 2260 Clove Drive, San Jose, California 95128 \\ Telephone: (408) $998-4554$ \\ FAX: (408) 998-2723}

June 27,1990

Ms. Lisa White

1347 Novellier street

El Cerrito, CA 94530

RE: Project entitled "Perceptions of occupational Therapy and the Rehabilitation Process by Patients Following Burn Rehabilitation: In-Depth Interviews"

Dear Ms. White:

On June 27, 1990, the Research and Human Subjects Review Committee for Santa Clara Valley Medical Center (an IRB holding Department of Health and Human Services Assurance \#M1306) approved your request to involve humans as subjects in research in the above referenced project. However, as communicated to you, the committee is concerned that discussion of the events that lead to the burn may be very traumatic for the individuals involved; therefore, provisions should be made for referring study subjects for psychological counseling if it seems appropriate. Dr. Patricia Hanley-Peterson of Psychology Services will be available to give you assistance on this matter. She may be reached at 408/299-5116.

Because the Committee recommended changes in the submitted consent form, approval is granted subject to use of the enclosed consent form which has been revised accordingly. If the revised consent meets with your approval, please endorse the attached copy and return it to the Administrator of the Committee, Carole Guthrie, in the envelope provided. If the revised consent does not meet with your approval, please submit proposed changes in writing for consideration by the committee.

In accordance with federal regulations, no changes may be made in the protocol or approved consent form without the knowledge and prior approval of the Committee. All adverse events/complications or problems having to do with subject safety must be reported to the committee within five (5) working days.

The number assigned to this approval is 6/22/90-03. It would be helpful if in future correspondence concerning this project, you would refer to this number. 
Ms. Lisa White

Page 2

June 27, 1990

In compliance with federal regulations, all research projects require continuing review at intervals appropriate to the degree of risk but not less than once per year. If the project is to continue beyond the expiration date of June 21, 1991, it must be renewed in accordance with the committee's renewal instructions. As a courtesy reminder, a renewal application will be mailed to you approximately two months prior to the expiration date.

Should you have any questions, please contact Ms. Guthrie at $408 / 998-4554$.

sincerely,

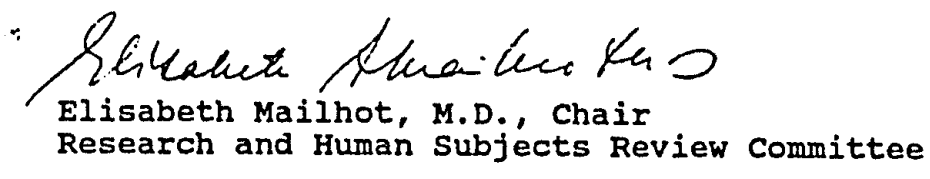

$\mathrm{EM} / \mathrm{cg}$

CC: Barry Press, M.D.

Patricla Hanley-peterson, Ph.D. 
APPENDIX C

\section{SUBJECT CONSENT FORMS}




\section{Alta Bates Hospital Subject Consent Form}

As we have discussed, you are invited to participate in a study of the perceptions of the patient with burn injury toward the rehabilitation process, your needs, and occupational therapy involvement. I expect the results of the study to eventually help us to determine how to better meet those needs.

You have been selected as a participant in the study because you suffered a major burn; you were treated at Alta Bates Hospital in Berkeley, CA; and you received occupational therapy services.

If you agree to participate, I will need to meet with you at a mutually agreeable time and location and will ask questions regarding your injury and the rehabilitation process. I have prepared questions as guidelines, but the interview is not limited to those questions, you may add any additional information you feel comfortable sharing.

With your permission, I will listen and take notes as well as tape record the interviews. We will most likely need between 2-3 hours to complete the interview. This time can be arranged at your convenience within a month period.

Any information that is obtained in connection with this study and that can be identified with you will remain confidential and anonymous and will be disclosed only with your permission or as required by law. If you give your permission by signing this document, I plan to disclose information you have given me regarding you perceptions and experiences in the burn rehabilitation process and occupational therapy anonymously. No names will be mentioned, and I do not anticipate that it will be possible for anyone to identify you as a participant in this study.

My study will be presented to the department of Occupational Therapy and San Jose State University and will be submitted for publication in an appropriate professional journal. 
I cannot and do not guarantee or promise that you will receive any benefits from this study. Other than the time you give to complete the interview, there will be no cost to you. You will not receive payment for your participation.

If you have any questions at any time, feel free to ask me directly (Lisa White, (415) 631-0484). Complaints about the procedures may be presented to Gordon Burton (advisor for graduate students) at (408) 924-3074; or Lela Llorens (Department Chair) at (408) 924-3070. For questions or complaints about research subject's rights, or in the event of research-related injury, contact Serena Stanford (Associate Academic vice President for Graduate Studies) at (408) 924-2480.

If you desire, you will be given a copy of this form to keep. YOU ARE MAKING A DECISION WHETHER TO PARTICIPATE. YOUR SIGNATURE INDICATES THAT YOU HAVE DECIDED TO PARTICIPATE AND THAT YOU HAVE READ THE INFORMATION PROVIDED ABOVE.

Date

Signature of Witness
Signature

Signature of Researcher 


\section{Saint Francis Memorial Hospital Subject Consent Form}

As we have discussed, you are invited to participate in a study of the perceptions of the patient with burn injury toward the rehabilitation process, your needs, and occupational therapy involvement. I expect the results of the study to eventually help us to determine how to better meet those needs.

You have been selected as a participant in the study because you suffered a major burn; you were treated at Saint Francis Memorial Hospital in San Francisco, CA; and you received occupational therapy services.

If you agree to participate, I will need to meet with you at a mutually agreeable time and location and will ask questions regarding your injury and the rehabilitation process. I have prepared questions as guidelines, but the interview is not limited to those questions, you may add any additional information you feel comfortable sharing.

With your permission, I will listen and take notes as well as tape record the interviews. We will most likely need between 2-3 hours to complete the interview. This time can be arranged at your convenience within a month period.

Any information that is obtained in connection with this study and that can be identified with you will remain confidential and anonymous and will be disclosed only with your permission or as required by law. If you give your permission by signing this document, I plan to disclose information you have given me regarding you perceptions and experiences in the burn rehabilitation process and occupational therapy anonymously. No names will be mentioned, and I do not anticipate that it will be possible for anyone to identify you as a participant in this study.

My study will be presented to the department of Occupational Therapy and San Jose State University and will be submitted for publication in an appropriate professional journal. 
I cannot and do not guarantee or promise that you will receive any benefits from this study. Other than the time you give to complete the interview, there will be no cost to you. You will not receive payment for your participation.

If you have any questions at any time, feel free to ask me directly (Lisa White, (415) 631-0484). Complaints about the procedures may be presented to Gordon Burton (advisor for graduate students) at (408) 924-3074; or Lela Llorens (Department Chair) at (408) 924-3070. For questions or complaints about research subject's rights, or in the event of research-related injury, contact Serena Stanford (Associate Academic vice President for Graduate Studies) at (408) 924-2480.

If you desire, you will be given a copy of this form to keep. YOU ARE MAKING A DECISION WHETHER TO PARTICIPATE. YOUR SIGNATURE INDICATES THAT YOU HAVE DECIDED TO PARTICIPATE AND THAT YOU HAVE READ THE INFORMATION PROVIDED ABOVE.

Date

Signature of Witness
Signature

Signature of Researcher 
BAHTA CLATA VALLEY MEDICAL CENTER

Bubjoot's conacot

TITLE OF BTODY: Perceptions of Occupational Therapy and the Rehabilitation process by patients Foliowing Burn Rehabilitation: In-Depth Interviews.

PRINCIPAL IXVEBTIOATOR: LIsa $K$. White, graduate student, san Jose State University, (415) 233-7997.

EXPLANATION OF BTUDY $A$ s we have discussed, you are Invited to participate in a study of the perceptions of the patient with burn injury toward the rehabilitation process, your needs, and occupational therapy involvement. The results of the study may help us to determine how to better meet those needs.

You have been selected as a participant in this study because you suffered a major burn; you were treated at santa clara valiey Medical Center; and you received occupational therapy services.

If you agree to participate, you will need to meet with me at a mutually agreeable time and location and you will be asked questions regarding your injury and the rehabilitation process. Questions have been prepared as guidelines; however, the interview is not ilmited to those questions and you may add any additional information you feel comfortable sharing.

With your permission, I will listen and take notes as well as tape record the interviews. The interview should take approximately 2-3 hours to complete. This time can be arranged at your convenience within a one month perlod.

RIBRB/DIBCOMPORTE: There are no known risks assoclated with your participation in this study. You may refuse to answer questions or terminate the interview at any time.

BEREFIT: There are no direct benefits assoclated uith your participation in the study.

ALTERHATIRE: The alternative to participating in this study 1s to choose not to participate. Your declsion whether or not to participate will not affect your access to treatment or tha guality of treatment you recelve from the county health system.

COBTE I Your participation in this otudy is on a voluntary basis and does not involve any cost to you. 
Conoont rorm, Pago 2

CONPIDENTIALITY: Information that is obtained in connection w1th this study that can be ldentified with you will remain confldential and anonymous and will be disclosed only with your permiselon or as required by low. If you glve your permission by signing this consent document, I plan to disclose information you have given we regarding your perceptions and experlences in the burn rehabilitation process and occupational therapy anonymously. No names will be mentloned, and I do not anticlpate that 1 t will be possible for anyone tq ldentify you as a particlpant in thio ctudy. The tudy will be presented to the Department of occupational Therapy and San Jose State University and will be aubmitted for publication in an appropriate professional journal.

COMPENBATION: It is the policy of the california Institute lor Hedical Research not to provide relmbursement for medical care or any form of compensation in the unlikely event of any physical or psychological injury sustained in the course of this research study. If problems occur, you should contact serena stanford (Ascoclate Academic Vice-President for Graduate studies) at (408) 924-2480.

BURJECT/PATIENT RIOHT: I understand that I am free to withdraw wy consent and discontinue participation in the study at any time without prejudice to me or effect on my medical care. My questlons have been answered; however, should I have additional guestions, I may contact Lisa White at (415) 233-7997. If I am not catisfled with the manner in which this study is being conducted, I may contact the Research and Human Subjects Review Comoittee which is concerned with protection of volunteers in research projecta. The comittee may be reactied by calling the offlce from 9:00 a.m. to 5:00 p.m. Monday through Friday, at (408) 998-4554, ext. 15 , or by writing to the Research Comoittee, California Institute for Hedical Research, 2260 Clove Drive, San Jose, California 95128.

HITNEBBING/BIGNATUREs: Your Gignature Indicates that you have read and understand the above information, that you have discussed this study with the Investigator, and that you have decided to participate based on the information provided. A copy of the signed and dated consent form vill be given to you.

signature of Subject

Signature of Witness

SIgnature of Investigator

Study Approved $6 / 22 / 90$
Date Signed

Date signed

Date signed 
APPENDIX D

INTERVIEW GUIDELINES 


\section{Interview Guidelines}

The following are preliminary interview questions and guidelines to provide at least minimal structure for the subject interviews.

1. Please tell me, briefly, about your history prior to the burn injury and after. Provide current demographic data.

2. Tell me about the injury; when and where it occurred; what you remember about the injury, etc.

3. Describe the acute (initial) phase of treatment.

4. Do you remember your first exposure to occupational therapy?

5. Did the occupational therapist(s) explain to you what the goals of the treatment were? What sort of orientation did the occupational therapist(s) give you? How did you feel after this orientation? Did you know what would happen; what was expected of you; what you could expect from therapy and the therapist? Did you feel reassured, anxious, etc.?

6. What is your understanding of occupational therapy in burn care? 
7. Do you feel you received the care you needed through rehabilitation? What was important to you in the rehabilitation process? Did you feel anything was missing?

8. Did occupational therapy use activities through the rehabilitation process? What were they? Did you understand the use of the activities?

9. What sort of follow-up contact/treatment did you receive, or are you receiving?

10. What sort of pain management techniques did you use?

11. How long did you receive occupational therapy treatment?

12. Did you work primarily with one occupational therapist or several?

13. Did you participate in establishing your own treatment goals?

14. What advice would you give to a new occupational therapist in the area of burn rehabilitation? 